J. Egypt. Soc. Parasitol. (JESP), 51(3), 2021: 517 - 524

(Online: 2090-2549)

\title{
TOXOPLASMA INFECTION AND PREGNANCY OUTCOME IN PREGNANT FEMALES IN SAUDI ARABIA: A SINGLE CENTER STUDY \\ By
}

ASHRAF G. TIMSAH ${ }^{1 *}$, KHALID HASSAN ALZAHRANI ${ }^{2}$, KHALID ABDUALRAHMAN ALZAHRANI ${ }^{2 *}$, and HAMDA MORSAA AZIZ ALGHAMDI ${ }^{3}$

Department of Microbiology, Faculty of Medicine, Al-Baha University ${ }^{1}$, and Department of Parasitology ${ }^{1}$, Faculty of Medicine Al-Azhar University, New Damietta City, Egypt, Medical students ${ }^{2}$, Faculty of Medicine, Al-Baha University, and Department of Obstetrics and Gynecology, King Fahd Specialist Hospital ${ }^{3}$ (KFSH), Al Baha, Saudi

Arabia $\left({ }^{*}\right.$ Correspondence: ashraftimsah 1@yahoo.com \& "Aabdualrahman@bu.edu.sa)

\begin{abstract}
Toxoplasmosis is a disease caused by Toxoplasma gondii. It is asymptomatic in the majority of immunocompetent individuals who contract it. When $T$ gondii infection is acquired during pregnancy, the parasite can be transmitted via the placenta to fetus, causing congenital toxoplasmosis. The present study assessed the seroprevalence of $T$. gondii among pregnant females in AlBaha, Saudi Arabia. Moreover, the aim was also to assess the consequences of infection during pregnancy among those females. Blood samples from 173 patients were used for detection of anti-toxoplasma $\operatorname{IgG} \& \mathrm{IgM}$. The results showed that $35(20.2 \%)$ were positive, of whom $33(19.1 \%)$ were $\operatorname{IgG}$ positive and $2(1.2 \%)$ were $\operatorname{IgG} \&$ IgM positive. Of the $33 \mathrm{IgG}$ positive cases ten with history of abortion, two history of congenital anomalies, three cases with history of intrauterine growth retardation, and two cases with history of preterm labor. All cases consumed not-well cooked meat, ten had pet-cats.
\end{abstract}

Keywords: Saudi Arabia Toxoplasma gondii, Pregnancy, Outcome,

\section{Introduction}

Toxoplasmosis is a protozoan disease caused by $T$. gondii, an intracellular parasite of worldwide distribution (Yamada et al, 2011), with about one-third of the world's populations were toxoplasmosis seropositive (Bodaghi et al, 2012). Wilking et al. (2016) in Germany reported that the Robert Koch Institute surveyed sero- $T$. gondii among adults for the first time and was $49.1 \%$. More than 40 million men, women, and children in the U.S. carry Toxoplasma gondii, but very few have symptoms because the immune system usually prevented the parasite from causing illness (CDC, 2018). In France fetal transmission, outcome was live birth in $95 \%$ of cases, with latent congenital toxoplasmosis in $90 \%$ of cases and symptomatic forms in $10 \%$ of cases, of which $1 / 3$ are severe and 2/3 moderate (Picone et al, 2020). In humans, the main oral source of infection was be eating or handling inadequately cooked or raw meat containing tissue cysts (bradyzoites), or consuming raw fruit, vegetables, or water contaminated with oocysts (Schlüter et al, 2014) or the risk of mother-to-child transmission, these zoonotic routes of infection were important where an infected woman for the first time during pregnancy (Cong et al, 2015). The close contacts with felines and exposure to soil contaminated with cats' feces were sources of infection (Ben Abdallah et al, 2013). Again, congenital toxoplasmosis, reactivated Toxoplasma-encephalitis in immunosuppressed patients as the AIDS, HIV or after stem cell or organ transplantation (Coster, 2013), and ocular toxoplasmosis was congenital significant clinical pictures (Saadatnia and Golkar 2012). Besides, congenital toxoplasmosis included hydrocephalus, microcephaly, intracranial calcifications, retinochoroiditis, strabismus, blindness, epilepsy, psychomotor, and mental retardation, petechiae due to thrombocytopenia, and anemia (McAuley et al, 1994), but sometimes congenital toxoplasmosis may be fatal (Kieffer and Wallon, 2013).

Epidemiological studies of $T$. gondii in the pregnant women showed significant variation in prevalence from $9 \%$ to $67 \%$ in Euro- 
pean nations (Nash et al, 2005; Maggi et al, 2009; Ramos et al, 2011; Lopes et al, 2012) and up to $92.5 \%$ in Ghana (Ayi et al, 2009). Global meta-analysis used strict criteria based on seroconversion and low IgG avidity reported that about 201.600 children annually suffered from congenital toxoplasmosis (Rostami et al, 2019),

As to Saudi Arabia, in Riyadh positive toxoplasmin skin tests among pregnant women were $22.1 \%$ (Shoura et al, 1973), and in Mecca positivity was same among female pilgrims (Morsy and El Dasouki, 1977). El Hady (1991) in Abha by IHAT found 31.6\% anti-Toxoplsama among pregnant women. Sarwat et al. (1993) in Mecca, Al Amari (1994) in Abha, Yanaza and Kumari (1994) in Al-Hassa and Makki and Abdel-Tawab, 2010) in Eastern Saudi Arabia detected antiToxoplsama antibodies among the blood donors. Besides, Abdel-Motagaly et al. (2017) in Egypt reported the transmission of toxoplasmosis infection by blood transfusion as well nosocomial by the needle stick-injury. Abdalla et al. (1994) in premature infants in Saudi Arabia, with different clinical pictures reported anti-Toxoplasma IgM positivity of $23.1 \%$. IgG-positivity varied from $9.13 \%$ in Hail Region to $39.43 \%$ in the Eastern Region (El Harthi et al, 2006). Between 2002 $\& 2020$, the seroprevalence of toxoplasmosis in humans was assessed by the Saudi demographics. Al Ghazi et al. (2002) by torch age-agents in pregnant women detected Toxoplasma $\mathrm{IgG}$ antibodies in $35.6 \%$, CMV total $\mathrm{IgG}$ antibodies were in $92.1 \%$, rubella IgG antibodies in 93.3\%, HSV-1 IgG antibodies in $90.9 \%$, HSV-2 IgG in $27.1 \%$, and VZV IgG antibodies in $74.4 \%$, but $0 \%$ seroprevalence rate for HIV-1. Ismail (2020) reported that approximately one-third of $\mathrm{Sa}$ udi Arabia populations had IgG seropositivity, and $6.4 \%$ had IgM seropositivity.

As to animals, Morsy et al. (1994) in Riyadh detected anti-Toxoplasma antibodies in rodents. Al Dakhil and Morsy (1996) in the Eastern Region reported anti-Toxoplasma anti- bodies in the Indian grey mongoose $(H$. edwardi). Also, Amin, AM, Morsy (1997) in Jeddah detected anti-Toxoplasma antibodies in butchers and slaughtered sheep and goats. In the human host, the parasites form tissue cysts, most commonly in skeletal muscle, myocardium, brain, and eyes; these cysts may remain throughout the life of the host. Diagnosis is usually achieved by serology, although tissue cysts may be observed in stained biopsy specimens

This study aimed to assess the seroprevalence of Toxoplasma gondii among pregnant females in Al-Baha District to determine the infection risk factors and the consequence during pregnancy.

\section{Materials and Methods}

Study population: The study was a hospital-based cross-sectional study. It took place in the King Fahd General Hospital (KFH) in Al Baha, Saudi Arabia, between $1^{\text {st }}$ February 2020 and $1^{\text {st }}$ February 2021. Pregnant mothers, in their first and second trimesters, who attended $(\mathrm{KFH})$ the antenatal clinic, were included. Among 173 blood samples collected sera were separated for detection of anti-Toxoplasma IgG and IgM by ELISA

Anti-Toxoplasma IgG \& IgM levels: Specific IgG \& IgM antibodies to T. gondii were measured using ELISA Kits (Enzywell Toxoplasma IgG \&IgM Kits, according to the manufacturer's instructions. The dichromatic spectrophotometer (Bio-Tek ${ }^{\circledR}$, USA) was used to measure absorbance of tested sera and control ones at 450nm. Results were measured semi-quantitatively by calculating a ratio of optical density (OD) value for samples to OD value of the positive and negative control ones. Sample was considered positive for the specific antibodies if its absorbance was more than the Cut-off ( $>1.3$ for IgG \& $>1.2$ for $\operatorname{IgM}$ ), and negative if it was less than 0.7 for $\mathrm{IgG}$ and 0.8 for $\operatorname{IgM}$. The test was repeated if there was any doubt or if the borderline results were $(0.7-1.3$ for $\operatorname{IgG} \&$ 0.8-1.2 for $\operatorname{IgM})$. This ELISA Kit have a sensitivity of $98 \%$ and a specificity of $10 \%$, without cross-reactivity when compared to other ELISA kits. 
Statistical analysis: Data were analyzed by SPSS 22.0 software package. The data were reported as means and standard deviation. Categorical data are reported as frequencies.

Ethical considerations: This study was approved by the Ethical Committee of King Fahd Specialist Hospital, Saudi Arabia. According to Helsinki (1964) as human experimentation developed originally in 1964 for the medical community

\section{Results}

Patients: One hundred seventy-three pregnant females were in the first and second semester, with ages ranged from 30 to 45 years (30.46 \pm 8.9$)$. Serologically $35(20.2 \%)$ were positive for anti- $T$. gondii antibodies. Of whom 33(19.1\%) were IgG positive and $2(1.2 \%)$ positive for both IgG \& IgM antibodies. Out of the 33 positive females for Anti-Toxoplasma IgG, ten cases with history of single and/or repeated abortions, and two women with history of congenital anomalyes, another two with a history of intrauterine growth retardation, and two cases had a history of preterm labor. All cases reported the occasional consumption of the undercooked meat. Ten women documented contact with cats. Details were given figures $(1 \& 2)$

\section{Discussion}

In the present study, total $20.2 \%$ and 1.2 were positive IgG and IgM respectively. A wide range of seroprevalence of toxoplasmosis was reported in different region in Saudi Arabia by several epidemiological studies as in Jazan (Aqeely et al, 2014), Makkah (Ismail et al, 2016), Al-Madinah (Imam et al, 2016), and Qassim region (Rasheed et al, 2021). These figures were lower than that reported in others Saudi Arabian regions; Al-Khobar (Al-Mulhim and Al-Qurashi 2001), Al Ahsa (Al-Mohammad et al, 2010), Riyadh (Almogren 2011), Khamis Mushait and Abha (Almushait et al, 2014), Aseer (Eida, 2015), and AD-Dawadimi (Alanazi et al, 2017), On the contrary the present results were higher than that reported in Hail (Abdel Galil 2014) and Arar (Alanazi et al, 2017). A rise in IgM titers is sufficient evidence of acute infection. By contrast, a single positive IgM titer can mean that the infection was acquired either during pregnancy or before conception. If the infection is acquired before conception, the fetus is very unlikely to be at risk for congenital toxoplasmosis (Van Kessell and Eschenbach, 2021).

In Arab Countries, Kamal et al. (2015) in Egypt reported high prevalence seropositive cases in age group of 21-30 years. Postdelivery adverse outcome was in $80.3 \%$ of high-risk pregnancy group compared to $20 \%$ of normal pregnancy group. Statistically significant was between seropositivity and living in rural area, low socioeconomic level, and the consumption of the undercooked meat $(P<0.05)$. Al-Adhroey et al. (2019) in Yemen reported $20.0 \%$ of women of which $12.9 \%$ were positive for only $\operatorname{IgG}$ and $7.1 \%$ were positive for both IgG and IgM antibodies. All the 546 pregnant women were seropositive for anti-CMV IgG. Of the 546 women, $40(7.3 \%)$ were positive or equivocal for IgM antibodies. All sera from the 40 women $(\operatorname{IgG}+/ \operatorname{IgM}+)$ showed a high or intermediate CMV IgG avidity index.

Others countries with low IgM seroprevalence were New Zealand; $0.2 \%$, South Korea, $0.1 \%$, and USA, $0.01 \%$, and IgG wide range of prevalence was $(53.8 \%)$ whereas the three lowest were Mexico; 7.2\%, South Korea; $2.1 \%$, and Canada; $0.2 \%$ (Bigna et al, 2020). Environmental factors that favor $T$. gondii transmission and infectivity, as well as differences in study populations, numbers of cats, diagnostic procedures, and living styles, may all play a role in these differences in the reported prevalence rates from different localities (Saleh et al, 2014).

The only definitive hosts for Toxoplasma gondii are members of family Felidae (domestic cats and their relatives). Unsporulated oocysts are shed in cat's feces, Although oocysts are usually only shed for 1-3 weeks, large numbers may be shed. These can live for a long period in the environment, especially in water or soil. Domestic cat contact 
is frequently listed as a risk factor (Rifaat et al, 1981). This agreed with the present study as the pet cats were found to be a risk factor for $T$. gondii. This also agreed with studies reported inFrance (Baril et al, 1999) and China (Liu et al, 2009). However, others found no link between Toxoplasma infection and the presence of pet cats (Gebremedhin et al, 2013; Mwambe et al, 2013). Mohammed et al. (2019) in Saudi Arabia reported T. gondii antibodies among stray cats (39\%) and pet ones (13\%). Frequent exposure to feline feces or failure to take preventive measures (e.g., not washing hands or wearing gloves) can significantly increase the chance of infection. Inadequate inspection and infrequent check up with the veterinary clinics could increase the risk of zoonotic diseases speared like Toxoplasma from pet to owners. Not only can stray cats contaminate the environment in an indiscriminate manner, but also many owners allow their indoor cats to defecate outside their homes. As a result, there is a considerable risk of $T$. gondii oocysts contaminating the environment and being transmitted to humans, and the prevalence was projected to be higher (Cong et al, 2015).

In the present study, all positive $T$. gondii cases reported the consumption of meat, suggesting that consumption of meat may be a risk factor for toxoplasmosis if it was not properly cooked. Significant association between toxoplasmosis and consumption of meat were reported (Liu et al, 2009; Wu et al, 2011; Gebremedhin et al, 2013; Andiappan et al, 2014). This recommended that $T$. gondii infection in cattle, sheep, and chicken in Saudi Arabia may be contributing risk which is supported by high prevalence rates of toxoplasmosis in these animals (AlAnazi 2011; Al Nasr et al, 2018).

The present study showed that toxoplasmois during pregnancy may be a cause of several forms of bad pregnancy outcomes. Out of 35 toxoplasmosis cases, ten cases had a previous history of abortion, 2 cases had history of congenital anomalies, three cases had a previous history of intrauterine growth retardation and finally two cases had a previous history of preterm labor. All cases reported the consumption of meat. Ten cases documented contact with cats. Previous reports supported the role of toxoplasmosis acquired during pregnancy as a risk factor for bad pregnancy outcome (Sahwi et al, 1995; Freeman et al, 2005; Olariu et al, 2011; 2019; Yamamoto et al, 2013).

\section{Conclusion}

The feasible strategy awareness to prevent congenital toxoplasmosis measures is needed to reduce the risk of infection. The main preventive measures relate to reducing the pathogen burden in the food chain; improving food hygiene; public education, especially of women of child-bearing age; and various precautions in immunosuppressed persons (including in transplantation medicine). Screening for $T$. gondii antibodies before marriage and during pregnancy, is a must to avoid the sources of infection. Avoiding stray and pet cats is a must to minimize zoonotic toxoplasmosis.

\section{References}

Abdalla, KF, El Fakahany, AF, Arafa, MAS, Salama, MMI, Morsy, TA, 1994: Congenital toxoplasmosis among prematures in Saudi Arabia. J. Egypt. Soc. Parasitol. 24, 3:643-8.

Abd ElGalil, S, 2014: Prevalence of seropositive toxoplasmosis in pregnant women in hail Region Int. J. Hlth. Sci. Res. 4, 10:66-71.

Al-Adhroey, AH, Mehrass, AAO, Al-Shammakh, AA, Ali, AD, Akabat, MY, et al, 2019: Prevalence and predictors of Toxoplasma gondii infection in pregnant women from Dhamar, Yemen BMC Infect. Dis. 19, 1:1089.

Abdel-Motagaly, AME, Ibrahim, AMA, Morsy, TA, 2017: An intervention program on blood protozoa acquired by needle stick injury and infection control. J. Egypt. Soc. Parasitol. 47, 2: 309-322

Al-Harthi, SA, Jamjoom, MB, Ghazi, HO, 2006: Seroprevalence of Toxoplasma gondii among pregnant women in Makkah, Saudi Arabia. Umm Al-Qura Uni. J. Sci. Med. 18:217-27

Al Amari, OM, 1994: Prevalence of antibodies to Toxoplasma gondii among blood donors in Abha, Asir Region, southwestern Saudi Arabia. J. Egypt. Pub. Hlth. Assoc. 69:77-88.

Al-Anazi, AD, 2011: Prevalence of Neospora 
caninum and Toxoplasma gondii antibodies in sera from camels (Camelus dromedarius) in Riyadh Province, Saudi Arabia. J. Egypt. Soc. Parasitol. 41, 1:245-50

Al-Mohammad, HI, Amin, TT, Balaha, MH, Al-Moghannum, MS, 2010: Toxoplasmosis among the pregnant women attending a Saudi Maternity Hospital: Seroprevalence and possible risk factors. Ann. Trop. Med. Parasitol. 104: 493-504.

Al-Mulhim AA, Al-Qurashi AM, 2001: Seroprevalence of toxoplasmosis in pregnant mothers and new born infants in eastern province, Saudi Arabia. J. Family Community Med. 8:45-8

Al Nasr, I, El-Ashram S, Huang S, 2018: Seroprevalence and genotyping of Toxoplasma gondii from free-range chickens in Qassim, Saudi Arabia. Jpn. J. Vet. Res, 66, 2: https://doi.org/ $10.14943 /$

Alanazi, AD, Alyousif, MS, Alomar, SA, et al, 2017: Seroprevalence and risk factors of Toxoplasma gondii infection among pregnant women in Ad-Dawadimi General Hospital, Kingdom of Saudi Arabia. J. Egypt. Soc. Parasitol, 47, 2:355 -62 .

Alanazi F, Hassan, T, Alanazi, W, 2017: Seroprevalence of Toxoplasma gondii among pregnant Saudi woman in Arar, Northern Borders Province, Saudi Arabia. Kasr Al Ainy Med. J. 23:104-8.

Al Dakhil, MA, Morsy, TA, 1996: Natural Toxoplasma infection sought in the Indian grey mongoose (H. edwardi, Greffroy, 1818) trapped in the Eastern Region, Saudi Arabia. J. Egypt. Soc. Parasitol. 26, 3:645-52.

Al Ghazi, HO, Telmesani, AM, Mahomed, MF, 2002: Torch age-agents in pregnant Saudi women. Med. Prin. Pract. 11, 4:180-90. Almogren, A, 2011: Antenatal screening for Toxoplasma gondii infection at a tertiary care hospital in Riyadh, Saudi Arabia. Ann. Saudi Med. 31:56-72.

Almushait, MA, Dajem, SM Bin, Elsherbiny, NM, et al, 2014: Seroprevalence and risk factors of Toxoplasma gondii infection among pregnant women in south western, Saudi Arabia. J. Parasit. Dis. 38:4-10.

Amin, AM, Morsy, TA, 1997: Anti-Toxoplasma antibodies in butchers and slaughtered sheep and goats in Jeddah Municipal abattoir, Saudi Arabia. J. Egypt. Soc. Parasitol. 27, 3:913-8.

Andiappan, H, Nissapatorn, V, Sawangjaro- en, N, et al, 2014: Toxoplasma infection in pregnant women: A current status in Songklanagarind Hospital, southern Thailand. Parasit. Vectors $7: 1-7$

Aqeely, H, El-Gayar, EK, Perveen, Khan D, et al, 2014: Seroepidemiology of Toxoplasma gondii amongst Pregnant Women in Jazan Province, Saudi Arabia. J Trop Med 2014:913950. https://doi.-org/10.1155/2014/913950

Ayi, I, Edu, S, Apea-Kubi, KA, et al, 2009: Sero-epidemiology of toxoplasmosis amongst pregnant women in the greater Accra region of Ghana. Ghana Med. J. 43:34-9

Baril, L, Ancelle, T, Goulet, V, et al, 1999: Risk factors for Toxoplasma infection in pregnancy: A case-control study in France. Scand. J. Infect. Dis. 31:305-9

Ben Abdallah, R, Siala, E, Bouafsoun, A, Maatoug, R, Souissi, O, et al, 2013: Toxoplasmosis mother-to-child screening: study of cases followed in the Pasteur Institute of Tunis (20072010). Bull. Soc. Pathol. Exot. 106:108-12.

Bigna, JJ, Tochie, JN, Tounouga, DN, et al, 2020: Global, regional, and country seroprevalence of Toxoplasma gondii in pregnant women: A systematic review, modeling and meta-analysis. Sci. Rep. 10:1-10.

Bodaghi, B, Touitou, V, Fardeau, C, et al, 2012: Toxoplasmosis: New challenges for an old disease. Eye (London) 26:241-4.

CDC, 2018: Parasites: Toxoplasmosis (Toxoplasma infection). Source: Global Health

Cong, W, Dong, XY, Meng, QF, et al, 2015: Toxoplasma gondii Infection in pregnant women: A seroprevalence and case-control study in Eastern China. Biomed. Res. Int. 2015:170278. https://doi.org/10.1155/2015/170278

Coster, LO, 2013: Parasitic infections in solid organ transplant recipients. Infect. Dis. Clin. North Am. 27:395-427.

Eida, A, 2015: Direct Genotyping of Toxoplasma gondii in blood samples from pregnant women in Jazan, Saudi Arabia. J. Egypt. Soc. Parasitol. 45:603-8.

El Hady, HM, 1991: Toxoplasmosis among pregnant women in Abha, Saudi Arabia.

J. Egypt. Soc, Parasitol. 21, 3:811-5.

Freeman, K, Oakley, L, Pollak, A, et al, 2005: Association between congenital toxoplasmosis and preterm birth, low birthweight and small for gestational age birth. BJOG, Int. J. Obstet. Gynaecol. 112:31-7. 
Gebremedhin, EZ, Abebe, AH, Tessema, TS, et al, 2013: Seroepidemiology of Toxoplasma gondii infection in women of child-bearing age in central Ethiopia. BMC Infect. Dis. 13:1-9 Ghazi, HO, Telmesani, AM, Mahomed, MF, 2002: TORCH agents in pregnant Saudi women. Int. J. Kuwait Univ. Hlth. Sci. Cent. 11:180-2. Imam, N, Azzam, E, Attia, A, 2016: Seroprevalence of Toxoplasma gondii among pregnant women in Almadinah Almunawwarah KSA. J. Taib. Univ. Med. Sci 11:https://doi.org/10.1016/ j.tumed. 2016.04.004

Ismail, K, 2020: Toxoplasmosis in humans and animals in Saudi Arabia: A systematic review. J. Infect. Develop. Countries 14, 8:800-811

Ismail, K, Bahathiq, A, Degnah, N, et al, 2016: Detection of Toxoplasma gondii infection and associated risk factors among pregnant women in Makkah Al Mukarramah, Saudi Arabia. Asian Pacif. J. Trop. Dis. 6:113-9.

Jenum, PA, Stray-Pedersen, B, Melby, KK, et al, 1998: Incidence of Toxoplasma gondii infection in 35,940 pregnant women in Norway, and pregnancy outcome for infected women. J. Clin. Microbiol. 36:290-6.

Kamal, AM, Ahmed, AK, Abdellatif, MZM, Tawfik, M, Hassan, EE, 2015: Seropositivity of Toxoplasmosis in Pregnant Women by ELISA at Minia University Hospital, Egypt. Korean J. Parasitol. 53, 5:605-10.

Kieffer, F, Wallon, M, 2013: Congenital toxoplasmosis. Handb. Clin. Neurol. 112:1099-101. Liu, Q, Wei, F, Gao, S, et al, 2009: Toxoplasma gondii infection in pregnant women in China. Trans. R. Soc. Trop. Med. Hyg. 103:162-6

Lopes, AP, Dubey, JP, Moutinho, O, et al, 2012: Seroepidemiology of Toxoplasma gondii infection in women from the north Portugal in their childbearing years. Epidemiol. Infect. 140: 872-7

Maggi P, Volpe A, Carito V, et al, 2009: Surveillance of toxoplasmosis in pregnant women in Albania. New Microbiol. 32:89-92

Makki, SM, Abdel-Tawab AH, 2010: Anti-Toxoplasma gondii antibodies among volunteer blood donors in Eastern Saudi Arabia. J. Egypt. Soc. Parasitol. 40, 2:401-12.

McAuley, J, Boyer, KM, Patel, D, et al, 1994: Early and longitudinal evaluations of treated infants and children and untreated historical patients with congenital toxoplasmosis: the Chicago Collaborative Treatment Trial. Clin Infect Dis an Off Publ Infect Dis Soc Am 18:38-72.
Mohammed, OB, Omar, OI, Elamin, EA, et al, 2019: Seroprevalence of toxoplasma gondii in household and stray cats of Riyadh, Saudi Arabia. Vet Ital. 55:241-5.

Morsy, TA, El Dasouki, ST, 1977: Toxoplasmin skin tests among some pilgrims in Saudi Arabia. J. Egypt. Soc. Parasitol. 7, 1:81-3.

Morsy, TA, Sabry, AA, Habib, KSM, Arafa, MAS, El Bahrawy AFA, et al, 1994: Antibodies against Toxoplasma in commensal rodents trapped in Riyadh, Saudi Arab-ia. J. Egypt. Soc. Parasitol. 24, 2: 279-84.

Mwambe, B, Mshana, SE, Kidenya, BR, et al, 2013: Sero-prevalence and factors associated with Toxoplasma gondii infection among pregnant women attending antenatal care in Mwanza, Tanzania. Parasit Vectors 6:1-5

Nash, JQ, Chissel, S, Jones, J, et al, 2005: Risk factors for toxoplasmosis in pregnant women in Kent, United Kingdom. Epidemiol Infect 133: 475-83

Olariu, TR, Press, C, Talucod, J, et al, 2019: Congenital toxoplasmosis in the United States: Clinical and serologic findings in infants born to mothers treated during pregnancy TT-Toxoplasmose congénitale aux États-Unis : Observations cliniques et sérologiques chez les nourrissons nés de mères traitées pendant la grossesse. Parasite26:13.https://doi.org/10.1051/parasite/20190. Olariu, TR, Remington, JS, McLeod, R, et al, 2011: Severe congenital toxoplasmosis in the United States: Clinical and serologic findings in untreated infants. Pediatr. Infect. Dis. J. 30:

Picone, O, Fuchs, F, Benoist, G, Binquet, C, Kieffer, F, et al, 2020: Toxoplasmosis screening during pregnancy in France: Opinion of an expert panel for the CNGOF. J. Gynecol. Obstetre. Hum. Reprod. 49: 7, September 2020, 101814

Ramos, JM, Milla, A, Rodríguez, JC, et al, 2011: Seroprevalence of Toxoplasma gondii infection among immigrant and native pregnant women in Eastern Spain. Parasitol. Res. 109: 1447-52

Rasheed, Z, Shariq, A, AlQefari, GB, et al, 2021: Toxoplasmosis in immunocompetent Saudi women: Correlation with vitamin D. Women Hlth.17:17455065211043844. https://doi.org/10. 1177.

Rifaat, MA, Morsy, T, Sadek, MSM, Mahmoud, AMK, 1981: Antibodies against some parasites in stray cats in Cairo. J. Egypt. Soc. Parasitol. 11, 2:517-24.

Rostami A, Riahi SM, Contopoulos-Ioannidis, 
DG, et al, 2019: Acute Toxoplasma infection in pregnant women worldwide: A systematic review and meta-analysis. PLoS Negl. Trop. Dis. 13: e0007807. https://doi.org/10.1371/journal.pntd.

Saadatnia, G, Golkar, M, 2012: A review on human toxoplasmosis. Scand. J. Infect. Dis. 44: 805-14.

Sahwi, SY, Zaki, MS, Haiba, NY, et al, 1995: Toxoplasmosis as a cause of repeated abortion. J. Obstet. Gynaecol. Tokyo 21:145-8.

Saleh, AMA, Ali, HA, Ahmed, SAM, Hosny, S M, Morsy, TA, 2014: Screening of Toxoplasma gondii infection among childbearing age females and assessment of nurses' role in prevention and control of toxoplasmosis. J. Egypt. Soc. Parasitol. 44, 2:329-42

Sarwat, MA, Ahmed, AB, Zamzami, OM, Fawzy, AFA, Morsy, TA, 1993: Toxoplasma gondii in Saudi blood donors: A serological study using 3 tests. J. Egypt. Soc. Parasitol. 23, 3:751-7.

Schlüter, D, Däubener, W, Schares, G, Groß, U, Pleye, U, et al, 2014: Animals are keys to human toxoplasmosis. Int. J. Med. Microbiol. 304, 7:917-29.

Shoura, MA, Morsy, TA, El Dasouqui, IT, 1973: Toxoplasmin skin tests in Riyadh, Saudi Arabia. J. Trop. Med. Hyg. 76, 10:254, London.

Swisher, CN, Boyer, K, McLeod, R, 1994:
Congenital toxoplasmosis: The toxoplasmosis study group. Semin. Pediatr. Neurol. 1:4-25

Van kessell, KA, Eschenbach, DA, 2021: Toxoplasmosis in Pregnancy. Global Library of Women's Medicine's: Welfare of Women Global Health Program.

Wilking, H, Thamm, M, Stark, K, Aebischer, T, Seeber, F, 2016: Prevalence, incidence estimations, and risk factors of Toxoplasma gondii infection in Germany: A representative, crosssec-tional, serological study. Sci. Rep. 6:2255

Wu, SM, Huang, SY, Fu, BQ, et al, 2011: Seroprevalence of Toxoplasma gondii infection in pet dogs in Lanzhou, Northwest China. Parasit. Vectors 4:1-5

Yamada, H, Nishikawa, A, Yamamoto, T, et al, 2011: Prospective study of congenital toxoplasmosis screening with use of $\operatorname{IgG}$ avidity and multiplex nested PCR methods. J. Clin. Microbiol. 49:2552-6.

Yamamoto, R, Ishii, K, Shimada, M, et al, 2013: Significance of maternal screening for toxoplasmosis, rubella, cytomegalovirus and $\mathrm{Her}$ pes simplex virus infection in cases of fetal growth restriction. J. Obstet. Gynaecol. Res. 39: 653-7.

Yanaza, A, Kumari, P, 1994: Prevalence of Toxoplasma antibodies in blood donors in Al-Hassa. Ann. Saudi Med. J. 14:23-30.

\section{Explanation of figures}

Fig. 1: Map of Saudi Arabia, red cycle surrounds Al-Baha Province, Saudi Arabia,

Fig. 2: Prevalence rates of anti- toxoplasma IgG and IgM among participants.

Fig. 3: Illustrative Toxoplasma gondii life cycle after CDC

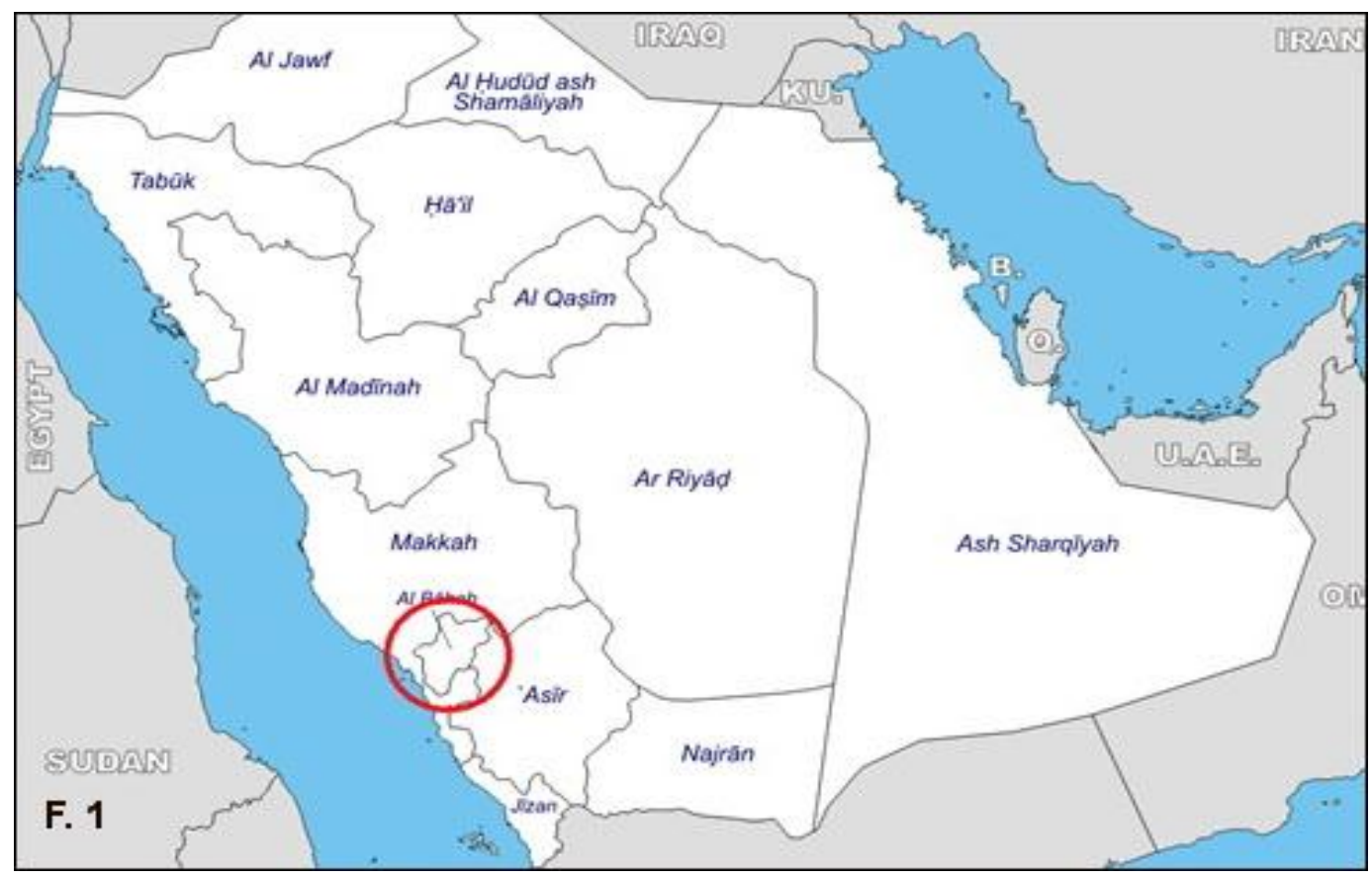



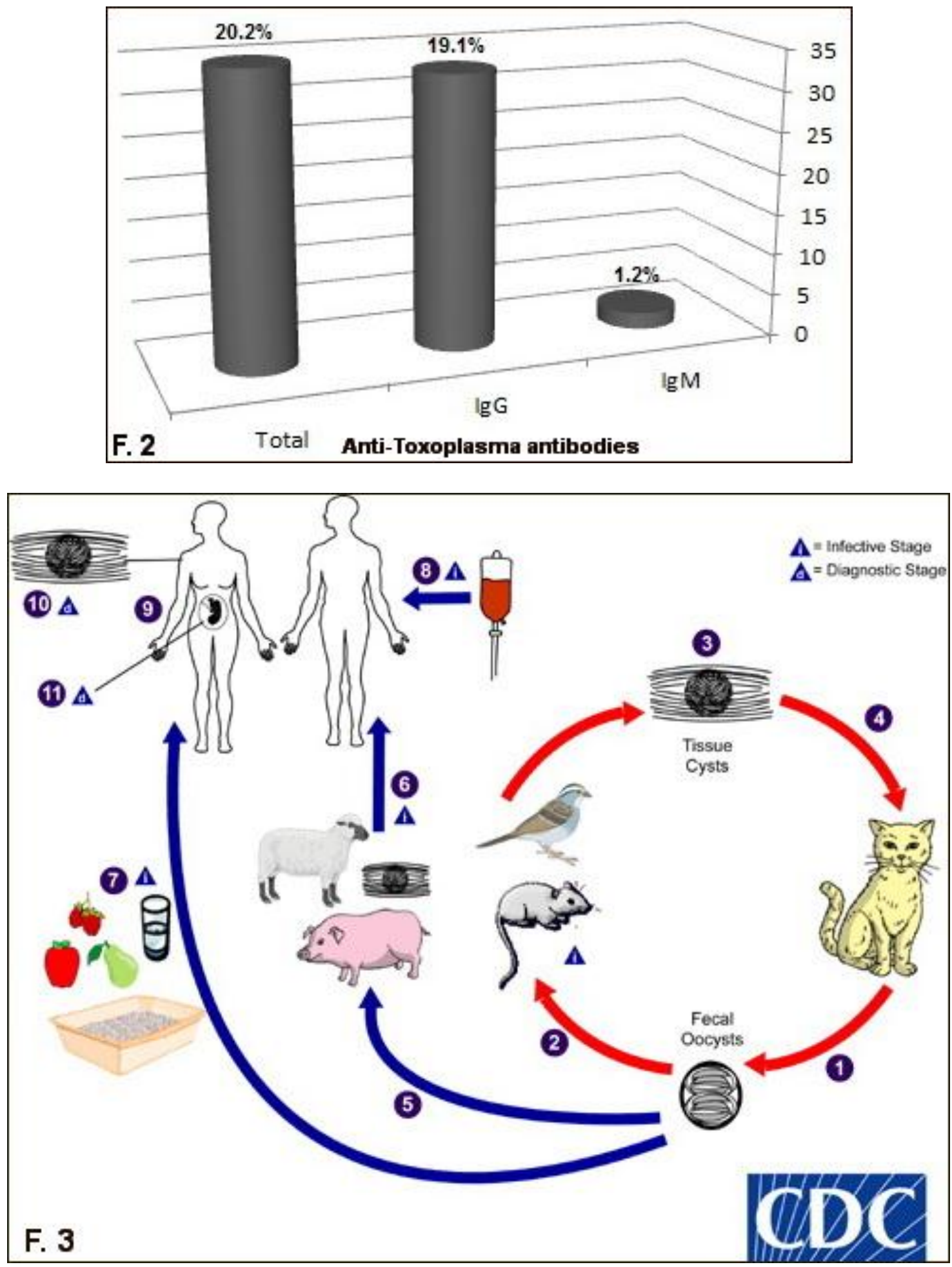